\title{
Flexible working, work-family conflict and maternal gatekeeping: the daily experiences of dual-earner couples
}

\begin{abstract}
This paper explores the impact of flexible working on the daily experiences of work-family conflict for dual-earner couples with child dependants. In exploring these daily experiences, the occurrence of maternal gatekeeping behaviours, and the relationship between flexible working and such behaviours, is investigated. We draw on episodic and longitudinal data from qualitative diaries kept for a one-month period by both members of 24 couples (48 participants) as well as from introductory and subsequent in-depth qualitative interviews with the couples, both together and apart. We report evidence suggesting that work-family conflicts are experienced and resolved differently, depending on whether it is the male or the female who works flexibly within dual-earner couples. This link between flexible working and gender is demonstrated to have an important impact on maternal gatekeeping behaviours, which are highlighted as playing a crucial role in such daily experiences and how they are resolved.
\end{abstract}

\section{Practitioner points}

- Traditional gender norms still play a role in parents' decisions to work flexibly and workers who opt for non-traditional routes may feel stigmatised.

- HR departments and employers need to promote the legitimacy of male access to flexible working and work-life balance policies so these are not perceived as opportunities for mothers alone.

- Greater father take-up of work-life balance initiatives that offer more opportunities for involvement in childcare should be encouraged.

- Employers should offer a variety of flexible working arrangements to provide employees with desirable and healthy resolution options when faced with incidents of work-family conflict. 


\section{Introduction}

The steady increase in women's participation in the workforce over the last forty years (Massarelli \& Wozowczyk, 2009; EHRC, 2008; Harkness, 2008) has led to an increase in dual-earner couples and a move away from the traditional male-breadwinner model of the family. This means that most workers, regardless of gender, now have an employed partner and both male and female workers increasingly have to integrate the goals and demands related to their families, their careers, and frequently their partners' careers as well (Moen $\&$ Sweet, 2002). Subsequently issues surrounding the occurrence and management of workfamily conflict, a form of inter-role conflict in which role pressures from the work and family domains are, in some respect, incompatible (Greenhaus \& Beutell, 1985), have become key. In response, governments across the globe have introduced a variety of policies that aim to enable employees to manage both their family and work responsibilities. Much of the legislation across countries has focused on part-time work and the right to request a reduction in working hours (Hegewisch \& Gornick, 2011). In the UK a variety of government work-life balance initiatives have been introduced over the last two decades. Indeed the current coalition government has very recently extended the right to request flexible working further to all employees, meaning that employers now have a duty to consider all requests in a reasonable manner (ACAS, 2013). Concurrently there has also been an increase in the variety of official flexible working arrangements available in organisations, from flexible working and homeworking to job-sharing and school term-time working (Wanrooy et al, 2013).

Despite this increase in awareness from policy makers and practitioners, research still reports significant gaps between the proposed idealised outcomes of flexible working 
arrangements and their reality (Kossek et al, 2010; Beauregard \& Henry, 2009). Numerous problems with the utilisation of these policies have been raised with a particular emphasis on stigmatisation (Gatrell \& Cooper, 2008; Coronel et al, 2010; Holt \& Lewis, 2011) and the proliferation of traditional gender stereotypes and inequality in the workplace and at home maintained by societal structures (Rapoport et al 2002; Brandth \& Kvande, 2001; 2009; Harkness, 2008; Morehead, 2005). Another possible contributory explanation that has received much less attention in the literature is the impact of 'maternal gatekeeping', defined as, "a collection of beliefs and behaviours that ultimately inhibit a collaborative effort between men and women in family work by limiting men's opportunities for learning and growing through caring for home and children" (Allen \& Hawkins, 1999:200). This highlights the possible role that women may play in limiting the involvement of their male partners on a daily basis.

This paper seeks to explore the impact that the use of flexible working within dualearner couples has on how daily work and family responsibilities are managed, as well as why this is the case. Therefore we are asking, what impact does flexible working have on daily practice within dual-earner couples and does gender play a role? We investigate this through an examination of couple's experiences of managing daily work-family conflicts.

\section{Flexible working}

Here we use the term flexible workers to refer to those who perceive themselves as having work that is flexible in the sense that they have control over their own schedules. In this sense we use the definition of Hill et al (2008, p.152) conceptualising flexible working as "the ability of workers to make choices influencing when, where, and for how long they engage in work-related tasks". Research suggests that flexible working is not just in the 
interests of employees. Flexible working has been championed by some companies in response to increased globalisation, competition growth and the consequential need for business to be conducted around the clock (Lewis et al, 2009). In this way, while flexible working practices may enable employees to manage both their work and caregiving responsibilities, they can also lead to an increase in time spent working further intensified by rapid technological advances blurring the boundaries between work and home (Fenner \& Renn, 2010). Employees may feel obliged or even pressurised to work longer hours as a form of reciprocation in terms of exchanging their own leisure time and an increase in effort for the perceived privilege of being permitted to work flexibly (Kelliher \& Anderson, 2010; Meyer et al., 2001) or to avoid losing a job that offers them such flexibility (Shepard et al., 1996). Furthermore part-time and flexible working have been linked to discrimination, low pay and reduced opportunities for promotion (Gatrell 2005, 2007, Gatrell \& Cooper, 2008; Coronel et al, 2010). Indeed the use of such policies can be highly stigmatised in that stereotypes abound those who take advantage of such policies as less committed to their work (Holt \& Lewis, 2011; Lewis \& Humbert, 2010).

\section{Gender Differences}

These stereotypes and subsequent stigmatisation can undermine the benefits of such policies as well as proliferating gender inequality in the workplace given that they are often seen to be aimed at women with young children (Rapoport et al, 2002; Wise \& Bond, 2003). Stereotypes of ideal workers differentially affect men and women with women being perceived as less able to meet these standards, therefore being rated lower in performance than male colleagues despite reporting similar levels of involvement in both work and family roles (King, 2008). Irrespective of the present government emphasis on the right to request 
flexible working for all employees (ACAS, 2013), research suggests that gender differences in the use of such policies prevail (e.g. Brandth \& Kvande, 2001; Brescoll et al, 2013) with women being more aware of the various flexible working options available and feeling more able to access such policies (Kersley et al, 2006). This undermines their intended focus on encouraging all employers to consider alternative ways of working in order to adapt to the changing world in which we live and work.

Other research has suggested that the experience of daily work-family conflict and lack of work-life balance might be more prevalent for women than men as they take on the majority of the housework despite their greater participation in the paid labour force (Kan \& Gershuny, 2010; Harkness, 2008; Crompton et al, 2005). Females also take on "additional labour" (Morehead, 2005) in the form of work needed to maintain arrangements that parents have in place such as arranging support, and mothers' managing father's domestic work or childcare responsibilities. Previous research has implied differences in the experiences of men and women in dealing with work-family conflicts with job stress being related to role conflict more often for women than for men (Greenglass, et al, 1988) and emotional exhaustion also reported to be stronger among female employees when compared to male (Posig \& Kickul, 2004). Such research suggests that it is important to acknowledge the differences in work-family conflict experiences of men and women.

\section{Maternal Gatekeeping}

There has been a great deal of research emphasis on the aforementioned stigmatisation, workplace inequality and gender stereotyping with regards to the notion of the 'ideal' worker. However, an additional possible explanation for such reported differences in the experiences of women as compared to men, which has received much less 
attention in the literature, is the impact of 'maternal gatekeeping' (Allen \& Hawkins, 1999). Maternal gatekeeping is conceptualized as the mother imposing some degree of restriction on the father's involvement with children (Allen \& Hawkins, 1999). More recently Puhlman and Pasley (2013) have suggested that this involves any attempt, conscious or subconscious, by the mother, to influence father involvement in, and interaction with, the children via controlling, facilitative, and restrictive behaviors. Allen and Hawkins (1999) suggest that over twenty per cent of mothers engage in this behaviour, and subsequently, while it is not suggested that this is the primary reason for the lesser involvement of men in childcare activities, this may be one factor playing a role in the disparity between the daily work-life experiences of the two genders. Such behaviours have been shown to occur regardless of the level of personal needs or objective difficulties experienced and can subsequently lead to tensions between couples due to the mother taking on a much heavier burden in terms of childcare, and the father feeling segregated from such activities (Kulik \& Tsoref, 2010).

It unclear as to whether gatekeeping is a product of low paternal involvement in parenting or a source of it, with more recent research arguing that it is both (Hauser, 2012). Kulik and Tsoref (2010) suggest that, as well as mother's gender role ideology; her evaluations of her partner's involvement in childcare are key in determining maternal gatekeeping behaviours. The more satisfied the mother is with her husband's involvement in child care, the more confidence she has in his ability to care for the children, and the greater her tendency to let him enter that territory. As mothers often feel pressures from perceived societal norms and intensive mothering ideals they may feel reluctant to seek support with childcare from their partner, or from others (Kilzer \& Pederson, 2011). This can also lead to mothers feeling that others, including their partners, are unable to provide 
adequate childcare without their guidance which in turn may act as a barrier to father's involvement and subsequently their paternal identity (Perälä-Littunen, 2007).

Despite the growing literature on maternal gatekeeping within the family studies discipline, the majority of research carried out in this area has been quantitative using survey questionnaires. No previous research has explored how maternal gatekeeping affects daily experiences in terms of managing home and work responsibilities and no research investigates this at the level of the couple, gaining the perspectives of both the males and females involved. Those qualitative studies that have explored maternal gatekeeping in greater depth have tended to focus on maternal gatekeeping in separated families, rather than within the context of couple households (e.g. Pruett et al, 2006; Trinder, 2008). There is a scarcity of in-depth examination of the role that women themselves might play in limiting the involvement of their male partners (Hauser, 2012), as well as the impact that maternal and paternal employment patterns might have on such behaviours, particularly on a daily basis (Meteyer \& Perry-Jenkins 2010; Pedersen \& Kilzer, 2014).

Recent research has found evidence suggesting that an increase in work-family conflict experiences might actually lead to females increasing gatekeeping behaviours in an attempt to protect their maternal identities (Pederson \& Kilzer, 2014). Despite findings indicating that maternal employment and subsequent increases in work-family conflict could actually exacerbate maternal gatekeeping behaviours, no research to date has explored how the use of flexible working might impact upon this relationship. It is possible that flexible working could ease work-family conflict experiences and therefore reduce maternal gatekeeping behaviour. Alternatively, flexible working could be one way in which women are enabled to maintain control over the home domain, therefore actually 
encouraging maternal gatekeeping to a greater extent and subsequently increasing their experiences of work-family conflict.

There is also currently no research investigating the impact that male utilisation of flexible working has on maternal gatekeeping behaviour. Flexible working can provide fathers with the ability to be more involved in childcare, which could threaten the traditional maternal role and lead to further encouragement of maternal gatekeeping behaviour (Kulik \& Tsoref, 2010). Alternatively, it seems plausible that greater opportunity for father involvement could reduce maternal work-family conflict, as well as providing greater opportunity to instil the mother with confidence in the father's ability to care for the children (Kulik \& Tsoref, 2010; Pederson \& Kilzer, 2014), therefore reducing maternal gatekeeping behaviour and leading to greater equality in balancing work and home responsibilities. These are questions that remain unexplored in the current literature but that have the potential to add to our understanding of the way in which flexible working could either help or hinder equality in how family responsibilities are managed within couples.

We are not suggesting here that maternal gatekeeping offers a replacement or conflicting argument to that which highlights the impact that societal institutions and structures play in the explanation of persistent gender inequalities. Rather, we consider the possibility that mothers may sometimes contribute to inequalities in the area of parenting to be an important issue that should be explored in greater depth. The links between such behaviours and flexible working utilisation within couples remains an area that could enhance our understanding of how such issues could begin to be addressed.

\section{The Context of the Couple}

[Type here] 
In the majority of work in this area, the impact of flexible working on work-non-work events, including studies exploring gender differences, has been investigated the level of the individual (e.g. Kossek \& Ozeki, 1998; Poppleton et al, 2008; Russell et al, 2009). This is despite the growing recognition that those balancing the demands of the work-family interface often do so within the context of a couple. There have been numerous studies calling for dyadic research using couples to investigate the dynamics of work-family conflict suggesting that such research has the ability to provide a more complete understanding of such experiences (e.g. Eby et al, 2005, Radcliffe, 2013). Research focusing only on the individual overlooks the complexities, both in terms of practicalities and emotions inherent when men and women attempt to coordinate their work and family commitments with those of their partners and with the needs of their families (Crouter \& Manke, 1997; Radcliffe \& Cassell, 2014; Sanz-Vergel et al, 2014).

Previous work-family research that has explored interactions within couples has reported the vital nature of the interdependence between partners. One of the few studies that did look at couples rather than individuals with regards to experiences of work-family conflict was by Hammer, Allen and Grigsby (1997), who found important crossover effects of work-family conflict between the two individuals within a couple and concluded by suggesting that future research focuses on the couple as the unit of analysis rather than the individual. Beyond crossover, individuals' choices are always shaped by the people in their lives therefore a realistic view of the individual as part of a system of interconnected individuals is fundamental to understanding how people manage their work and family responsibilities (Moen \& Sweet, 2002, Bluestein, 2001). Poppleton and colleagues (2008) observed that work-non-work conflict can originate from the responses of partners, 
becoming an interpersonal process, which is a relatively new idea in the work-family literature. They refer to Perlow's (1998) study of managerial boundary control which identified 'resister' spouses who can exacerbate work-non-work difficulties faced by their partners by, for example, setting limits on what they are prepared to accept in terms of their partner's work demands. Based on her findings she concluded that work-non-work conflict is underpinned by an interpersonal, rather than merely an intra-psychic, process. A focus on the use of flexible working arrangements and maternal gatekeeping behaviour within the partnership of couples could help individuals, couples, and organizations better understand how the availability of flexible working for each partner can affect the dynamics within the couple, their experience of work-family conflict and how they manage their workfamily responsibilities together on a daily basis.

\section{Other limitations in the work-life literature}

Greenhaus (2008) noted that a number of reviews of the field have drawn attention to some of the theoretical and methodological limitations in our knowledge and understanding of this area (e.g. Casper et. al., 2007). As noted by Eby et al (2005) in their review of the work-family literature, industrial-organizational psychology research has tended to focus on the centrality of the work role rather than the family role in people's lives. This overemphasis on the work domain results in a limited perspective on the totality of work-family experiences. Furthermore the focus of the majority of previous research upon a 'levels' approach where conflict is conceptualized and measured as a consolidated level makes it difficult to capture any of the specific details regarding how flexible working impacts upon work-family conflict events or the role that maternal gatekeeping might play. 
An alternative approach focuses upon events and episodes. Much of the extant episodic research concerns the relationships between conflict, mood and other outcomes, using daily diaries or surveys exploring how mood can spill over across domains (Poppleton et al., 2008; Butler et al, 2005; Sanz-Vergel et al, 2014). Other research investigates interpersonal crossover effects, which refers to the impact that one person's mood has on those closest to them (e.g. Bakker et al., 2009; Sanz-Vergel et al, 2014). However to date, there has been a scarcity of research that has taken an episodic approach in exploring the impact of flexible working on how couples manage daily work-family responsibilities. One exception is research conducted by Poppleton, Briner and Kiefer (2008) who collected daily diary data on work-non-work events in two contrasting organisations. They found that high levels of work to non-work facilitation and work to non-work conflict were reported in the flexible organisation whereas high levels of both positive and negative spillover from work to non-work and vice versa were found to be more predominant in the less flexible organisation. Work to non-work conflict was actually lower in the less flexible organisation with the implication that routine and predictability of working patterns may have exerted a protective effect. Poppleton et al (2008) emphasised the advantages of taking an episodic approach in terms of capturing immediate assessments of daily experiences in relation to flexible working, enabling more accurate judgments of the impact of such working arrangements, based on real and experienced events.

The current research uses in-depth, qualitative daily diaries to explore the role that flexible working plays in how dual-earner couples deal with daily incidents of work-family conflict, the dynamics involved and the subsequent outcome of the resolutions made. Using couples as the unit of analysis permits the exploration of the impact that flexible working 
availability across partners within dual-earner couples has on how work-family conflicts are experienced and managed on a daily basis including the role that maternal gatekeeping might play. The research questions addressed are:

- What is the impact of flexible working on couples' daily experiences of managing work-life conflict?

- What impact, if any, does gender have on these experiences?

\section{Method}

Forty-eight people took part in the study comprising of twenty-four dual-earner couples (meaning that both parties were involved in paid work outside the home) who were also responsible for child dependents. Participants were from a variety of organizations and occupations from both the public and the private sector. Access to flexible working was not an initial selection criteria for involvement in the study and therefore participants' access to flexible working was mixed. At least one person within eighteen of the twenty-four couples identified themselves as working flexibly and there were four couples within which both partners discussed having flexible working arrangements. Participants were recruited during spring 2009 using self-selection and snowball sampling. An information sheet explaining why the research was being carried out and what was involved in taking part was presented to potential participants. This was initially distributed around organisations where the authors had known contacts and subsequently passed on to relevant known others by participants. Each initial interview was conducted by the first author and lasted between 30 and 90 minutes. These interviews took place in the interviewees' own homes, with both members 
of the couple present. Details of the sample and their occupations can be found in Table One. All names have been changed to protect the identity of the participants.

[Insert Table One about here]

Initial interviews began with demographic questions before focusing upon areas of difficulty with regard to work-family conflict, how decisions were made, and potential conflicts resolved. Interviews were audio-recorded and transcribed verbatim for analysis. All participants were then given a diary to keep individually for four weeks where they were asked to report all incidents of work-family conflict experienced and the consequent decisions made as and when they occurred. Four weeks later, when the couples had completed the diary, they were given a second follow up interview, this time individually. This acted as an opportunity for participants to discuss any issues that had been raised while completing the diary, whilst also providing an opportunity to follow-up on any important discussion points. During the initial interview clear and detailed instructions were provided with regards to what participants were being asked to record in their diaries, including the necessary level of detail. The inclusion of minor, routine work-family conflicts was also stressed along with reference being made to specific examples.

Forty-three decisions were reported in participants' interviews and 255 daily conflict episodes were reported within their diaries. Nearly one third of these conflicts (seventy-six) were reported as being resolved by utilising flexible working of either (or both) partners. Entries were reported on around twenty percent of observed diary days, which was considered a good response rate. Response rates varied between participants with some recording entries and reporting conflicts more frequently than others. The least number of conflicts reported throughout the four-week diary period was three and this was by Nigel. 
The greatest number reported was fourteen by both Janet and Marissa. The sophistication of responses recorded within the diary entries also varied. While some participants provided greater depth in their responses including their accompanying thought processes, others provided much less detail, particularly in terms of their own reasoning, when recording these incidents. For these participants, follow-up interviews were particularly important and informative with regards to gaining extra insight into the incidents discussed in their diaries. In this way, using diaries in conjunction with interviews helped to counteract some of the limitations of using either method alone and allowed for a detailed picture of events and experiences to be captured (Radcliffe, 2013).

Transcribed interviews were analysed along with the diary data using a thematic template (King, 2004). The interview transcripts and diary data were first read with a broad view of exploring how couples managed work-family conflict situations and the different factors impacting how resolutions were made. The initial template was developed by the first author who examined a sub-set of the transcript data (diaries and interviews from one couple), and defined codes in light of the research question regarding experiences of workfamily conflict and decision making. Codes were organized hierarchically with the highestlevel codes representing broad themes and the lower levels describing more narrowly focused themes within these broader themes (King, 2004). The full sets of transcripts and diaries were then worked through systematically, identifying those sections of text that were relevant to the research questions and marking them with the corresponding code from the initial template. Further changes were then made to the template; involving the grouping together of several themes. For instance, 'the availability of flexible working' was incorporated as a lower order theme under the broad theme of 'available support', which 
was grouped under the main theme of 'enabling and constraining factors'. This more effectively described the impact that the availability of flexible working was having on participants' decision making. This template then served as the basis for interpretation of the dataset along with additional across couple comparisons. These comparisons were carried out on individual work-family incidents so that perceptions and descriptions of the same event from two different viewpoints could be analysed. There was great consistency between the conflict incidents reported within each couple with each account frequently including additional information leading to a more detailed picture of what had occurred. Notably, numerous incidents were reported by female participants that were not recorded by their partners. We now turn to the outcomes of this analysis.

\section{Findings}

In this section we focus on the impact that the availability of workplace flexibility had on couple's daily experiences of work-family conflict, with a focus on the gender differences that were highlighted in our findings.

\section{The daily impact of women having greater flexibility}

Where women had a more flexible job than their partner they tended to take on the majority of the family responsibilities thereby increasing the pressures upon them. This was demonstrated by Janet who reported feeling frequently stressed due to the flexible nature of her job and the constant feeling that she should be attending to responsibilities in both domains. For example in her diary she discussed an incident when their son was off school ill: 
"If I take annual leave I will be short for the rest of the leave period.... But if I work from home I will be stressed as not able to concentrate on either task....Decided that son not too ill so should be able to manage"

Her partner Rick was not discussed in Janet's consideration of any possible conflict resolution strategies and he did not mention this incident in his diary, highlighting how Janet strived to deal with such conflicts on her own. Where the woman had the more flexible job this tended to relinquish their male partners from the majority of the family responsibilities. Indeed there were numerous instances where women reported a conflict in their diary that was not mentioned by their male partner in his diary. Sole ownership of work-family conflict resolution by the women with job flexibility was however recognised in comments made by their partners in their interviews. For example, Tom stated that "Generally when making decisions I just go with what Julie says!" and when Adam was asked about his role as parent, he said "Well, erm, I suppose I just do what I can really". His partner Sarah acknowledged taking on this responsibility stating that "it is me who sorts out the childcare". In his followup interview Ben reported that he had "struggled a little bit" to find many conflicts to report because "Sylvia [his partner] is a born organiser anyway and I just go along with it and go with the flow. Sylvia organises everything." Similarly, in Adam's follow-up interview he explained that he

"...struggled a bit because Sarah does most of it with the kids.... if it's going to take all day it's usually Sarah who stays at home. She can take time off work better than I can I suppose" 
The females who worked more flexibly did not tend to acknowledge this inequality, but rather accepted this as normal and expected. For instance Hannah and Jane both explained why they tended to be more involved in resolving daily work-family conflict incidents:

Hannah: "He just sort of goes to work and comes home and he doesn't really get involved because his hours are longer than mine so it's easier for me to leave work if necessary than him really"

Jane: "It is ok to change my day off because my job is very flexible so I can just send my boss an e-mail saying I won't be in tomorrow and I will be in on Thursday instead. It is a lot less hassle for me to stay off work than for Mike"

Within these relationships then, men were shielded from the daily conflicts that arose. This was further highlighted in their diary entries, where they reported very few work-family conflicts. Therefore males and females appeared to differ in their involvement in the decision-making process needed to resolve a conflict. Indeed when women had the more flexible jobs, their male partners often failed to experience regular daily incidents of workfamily conflict because of their lack of involvement in the resolution process.

A different, but possibly concurrent, perspective can be understood in diary entries by both Janet and Rick. In her diary, Janet described a work-family conflict that occurred due to a work call over-running. She was "Panicking when it got to 5:10pm as the kids would be home and Gregory needs to be out again at 5:45pm." However, in her partner Rick's diary entry it became clear that he was already home from work and able to take their son to his self-defence class without any problem: 
"Janet had a panic because she was late home - no sweat really I took Gregory to self-defence and had tea later on"

This implies that Janet takes on this responsibility even when her partner is available to help. She expressed concern about whether or not her partner would be able to organise this in her absence, saying that she "wondered if Rick would get him out on time". Examples such as this highlight the possibility that in some cases women may be reluctant or unwilling to relinquish their control in the home domain. In their interview, Nick talked about how they were "at least trying to balance out who takes time off work" but that his partner Angela actually "takes more time out of work than I do". When asked further questions about the reasons for this they explained that:

Nick: "She's [their daughter] still obviously at an age where you know she's still very young and attached and Angela's not necessarily wanted to leave her when she's really ill so that sometimes comes into it"

Angela: "But like in that first week she was like Nick could have had her but I didn't want to.... couldn't have left because she was still so weak."

It may be that women still view this as their maternal role and, as this is likely to be regarded as a highly important role to their self-concept, this causes them to be reluctant to relinquish part of it to their partner. Alternatively, women may simply be accustomed to taking on this role. Either way this leaves less room for input from their partners. Olivia and Ray also discussed this in their interview:

Olivia: But you get ratty but like if it's something to do with Marcus [their son] I always think it's my responsibility to do it and he gets ratty because he thinks dads 
get left out. He always wants to do it so we do argue then, not argue, but we do disagree. If it's only one of us that can go from school he'll say no I'm going and I say no I'm going! You do though don't you? That's the only time we disagree isn't it really?

Ray: Yeah because I think everything is aimed at mums.

Olivia: Oh he has a big thing about this!

Ray: It used to be mother and baby parking spaces and its mother and baby toilets....

Olivia: You have a big thing about it. You know like when they send forms or something for parents to sign I always just get them out of Marcus' bag and fill them in and he's like why can't I sign it? I'm his dad!

Ray: Why can't I do that? I want to do that!

This not only highlights how in some cases women may be inclined to automatically take on this role, leaving little opportunity for their partner to be involved, but also serves as a reminder regarding the impact that society still has on this gender divide. In many social settings the focus remains on women as the primary carer of the child, which therefore puts restrictions on men who do want to take on this role.

\section{The daily impact of men having greater flexibility}

As mentioned above, males and females appeared to differ in their involvement in the decision-making process required to reach a resolution to a conflict and hence whether or not they actually experienced an event as a conflict. When males had the more flexible jobs females remained highly involved in the resolution process therefore still experiencing 
all conflict incidents themselves. While those men whose partners worked flexibly often failed to report incidents of work-family conflict that were reported in their partners' diaries, there were no conflicts recorded in male participants' diaries that were not at least mentioned in their female partners' diaries. This was still the case for those females whose partners had substantially greater flexibility at work than they themselves had access to.

Females who had limited flexibility at work, but whose partners had fairly flexible jobs, continued to report frequent daily conflicts in their diaries highlighting their active involvement in daily family-related activities. For example, Lucy's partner Paul had a particularly flexible job which she frequently relied on, however, she still reported daily conflicts throughout her diary including those related to the daily picking up and dropping off of the children which sometimes conflicted with meeting the requirements of her set work schedule. A similar situation was observed in Jasmine's diary. Despite her partner working flexibly; while her work hours were fairly rigid, she reported numerous daily conflicts. For example, she reported an incident where she had taken her son to a hospital appointment before school which lasted longer than anticipated and therefore meant she would be late arriving at her own workplace. In this instance she did not rely on her partner's more flexible job but resolved the incident with her employer:

"I rang my boss and said you've got two options, either I'm going to have to bring Jack with me or I'm going to be late. He said right, just bring Jack with you."

These findings highlight that whilst a woman's flexible working arrangements might to some extent shield their partners' from the experience of daily work-family conflicts; when men worked flexibly this did not have the same shielding effect for their female partners. 
Although women did discuss their partner's job flexibility as being extremely helpful this did not prevent them from experiencing daily conflicts themselves.

Women whose partners had more flexible jobs were still actively involved in the resolution of the conflict, even when they were unable to resolve the conflict themselves directly. For example, Edward had a much more flexible job than his partner Linda and he was usually able to work from home. They relied on his flexibility to resolve many of the daily childcare issues, such as providing childcare during the summer holidays. Despite this they both reported the same incidents throughout their diaries showing that the daily conflicts were experienced and felt by them both and therefore discussed and resolved together, even if she was unable to actively help with childcare. For instance on an occasion when her partner was unable to work from home during the summer holidays, Linda explained:

"We both spoke about leaving the boys home alone but felt that 3 hours was too long so we discussed alternatives....Decided to ring the mother of one of our youngest son's friends to see if he could go and play there for a few hours"

This demonstrates not only that she experienced this incident as a conflict but also that she was involved in its resolution despite being unable to take the time off work herself. Edward also wrote in his diary that he "was uncomfortable leaving the boys home alone for that amount of time". This type of synchronicity was common throughout their diary entries. A similar pattern could be seen in conflicts reported by other couples where the male had the greater job flexibility. For instance, Steve was the only male participant to work part-time and he also worked flexibly. Despite this his partner Melanie still reported regular workfamily conflicts in her diary. For instance, if he was unable to look after their daughter at a [Type here] 
time that he normally would, she would discuss this in her diary as a conflict that she was also working to resolve. This was a stark contrast to those couples where the man had the less flexible job in which case, as previously demonstrated, they often appeared uninvolved and in many cases, did not even acknowledge the conflict in their diaries.

Two of the couples in the current study recognised the males as the primary carers of their children, which, although the females still appeared to be actively involved in resolving any work-family conflict issues, appeared to be a sensitive subject. For Melanie and Steve this came about due to external circumstances as he was made redundant shortly before their daughter was born. Linda and Edward, who both worked full-time but with the majority of his work carried out flexibly and from home, appeared reluctant to discuss the reasons behind their decision to rely on Edward as the primary carer. In their interview, they appeared defensive in their answers surrounding this topic and when discussing this particular decision Linda said:

"I will be very honest with you; I think Ed takes more of the responsibility for that.

That's a choice that we've made that he takes more of the responsibility because he's the main carer. It's a personal choice. If we could just leave it at that."

The implication here is that such a decision, which goes against traditional gender norms, is still not an easy choice to make due to the expectations about parental norms that remain within our society. Whilst men having greater flexibility can lead to increased equality in managing the responsibilities of the home domain there may still be some resistance to challenges to traditional gender roles. 


\section{Discussion}

In answer to the research question exploring the impact of flexibility on couples' daily experiences of managing work-life conflict, our findings suggest that there is a differential impact depending on who has the flexible job. Men and women differed in their involvement in the decision-making processes associated with incidences of work family conflict. Where women had the more flexible job, they often took complete responsibility for resolving the conflict and their male partners rarely recognised the incident as such. Where men had the more flexible job, the women took an equal role in seeking to resolve the conflict. Although other studies have highlighted the protective effect of jobs for some people who have limited flexibility at work (e.g. Poppleton et al, 2008), by conducting daily diary studies with both members of a couple we have highlighted the impact that such protection for one member of a couple, can have on their partner on a daily basis. These findings also concur somewhat with previous research demonstrating that men tend to receive more support from their spouse than vice versa (e.g. van Daalen et al, 2005). Previous research has implied differences in the experiences of dealing with work-family conflicts for women and men. Examples include; job stress being related to role conflict more often for women (Greenglass, Pantony \& Burke, 1988), and women having greater difficulty in achieving control over competing demands generated from the various roles (Duxbury \& Higgins, 1991). Furthermore, the relationship between family-work conflict and emotional exhaustion is stronger among female employees when compared to male employees (Posig \& Kickul, 2004), and gender moderates the relationship between familywork conflict and job performance with the relationship being stronger among female employees (Yavas et al, 2008). Our analysis regarding the relative amount of responsibility 
taken on by women in the home domain, particularly when it is the female who works flexibly, could provide some explanation for these findings.

Our findings also suggest that one explanation for this imbalance might be the reluctance of women to relinquish or even share the primary care-giving role. Such reluctance has been discussed previously in the literature where it has been referred to as 'maternal gatekeeping' (e.g. Allen \& Hawkins, 1999; Beitel \& Parke, 1998). Rosenbaum and Cohen (1999) noted that there are some cases in the literature which suggest that the stress of working mothers is due to their perceptions of the impact of outside employment on their role as mothers. It is possible that some women perceive a threat to their maternal role; a role which is highly important to their self-concept, and are therefre reluctant to be less involved in this role by sharing the responsibility with their partner. It may also be that women are simply accustomed to taking on this role, leaving less room for input from their partners. Brandth and Kvande (2001) explored the success of paternal leave schemes in Norway by investigating new parent's decisions to take up either a standardised paternal leave allocation, where fathers receive a single block of 4 weeks leave, or a more flexible system of leave where negotiations are made between the mother, father and employers, to share the entire parental leave period between the mother and father. Their findings demonstrated that the majority of fathers made use of the standardised paternal leave allocation and very few engaged in the more flexible shared parental leave. One of the main reasons given for the limited uptake of this scheme was attitudinal, with mothers who returned to work rather than taking the full parental leave being viewed negatively by others for not being at home with their children, and fathers facing similar negative judgements for spending time away from the workplace. 
For both women and men, the perceived negative judgements of others are important. Burnett et al (2010) argued that the cultural climate is fraught with traditional and gendered perceptions of family roles and the validity of long hours and strong workplace presenteeism will inevitably impact upon the uptake of work-life balance policies. They concluded that "a conceptual shift of what it means to be a good father has not yet been widely accommodated" (Burnett et al, 2010, pg. 167). Another survey of stay-at-home fathers found that thirty-six percent of them experienced "a general prejudice toward men in traditionally female roles" (Rochlen et al, 2010, pg. 283). So although work and family responsibilities may be becoming more equally balanced within many dual-earner couples, there still remain important gender differences. The ideas of what it means to be a "good mother" and a "good father" have been internalised over previous generations and still work to maintain traditional gender roles by internal standards and societal norms. As Crompton and Brockman (2006) explained "centuries of ideological renditions of 'the feminine' and gender socialization and normative expectations, render it extremely likely that women will carry out more care work than men" (Crompton \& Brockman, 2006, pg. 119). Although conceptual shifts are underway, and ideas about these roles are changing, this is a slow and gradual process and is still in the transitional stages creating a conflict between the traditional and more modern gender roles.

At the start of this paper we stated that we intended to investigate how flexible working works in daily practice within dual-earner couples and in what way, if any, gender has an impact on such daily experiences. The findings presented here suggest a continued, but perhaps more subtle, gender divide. The females using flexible working experienced an increase in demands from the home domain with little help from their partner; whereas this 
effect was not present for males who worked flexibly due to the continued support provided by their partner. Therefore the experiences of dealing with daily work-family conflicts were somewhat different for males and females, impacted by the different gendered expectations placed upon them both internally and externally. Our findings suggest that, when females work flexibly, gender stereotypes are more easily perpetuated and traditional roles tend to be reverted to. However, as the woman is also working this can lead to an intensification of responsibilities in different domains and an increase in workfamily conflict. Interestingly one possible explanation for this highlighted in our findings was that female utilisation of flexible working can enhance maternal gatekeeping behaviour as mothers may be more inclined, and become accustomed to, taking on full responsibility for home related tasks, rather than allowing their partners to help. When females have greater flexibility than their male partners there is more opportunity for this pattern to become perpetuated as males are less frequently available to be involved in childcare and therefore females are less likely to gain confidence in their competence in the parenting role. This is in accordance with previous research findings suggesting that the mother's evaluation of her husband's involvement in childcare is a key factor affecting the occurrence of maternal gatekeeping (Kulik \& Toseref, 2010). Conversely, when men do work in roles where they have greater flexibility, our research suggests that this goes some way to helping couples to progress towards greater equality in terms of managing family responsibilities on a daily basis. When males worked more flexibly the existence of maternal gatekeeping was seen to be somewhat less prevalent, yet females did still remain actively involved in childcare tasks. In this way a more equal partnership was demonstrated where men had the space to be more involved in daily childcare activities. 
More research into the impact of flexible working on maternal gatekeeping is needed here. However, the current findings suggest that female flexible working may encourage maternal gatekeeping to a greater extent and that males working flexibly can actually help to break down this cycle. If more equality were to become the norm then this would provide the possibility that gender stereotypes and traditional gender norms will begin to erode. If such "family friendly" policies are to have the desired effects, the current research emphasises the importance of encouraging men to utilise these policies, rather than maintaining the usual female focus in policy implementation. Therefore, human resource professionals should be encouraging all employees, regardless of gender, to achieve a genuine balance between their work and non-work responsibilities.

Whilst the in-depth qualitative nature of this study enabled rich insights into the dynamics of decision-making and the utilisation of flexible working in instances of work-family conflict in a real time setting, there were also some limitations that should be addressed. The nature of the decision-making processes reported here is clearly a function of the individuals who participated in this study. The present research focused upon dual-earner couples; a factor that will undoubtedly have had a large impact on the daily utilisation and impact of flexible working experienced and reported. It is likely that such arrangements could become of even greater importance where less support in the home domain is available. For single fathers in particular, unique difficulties could be faced in terms of access to family-friendly policies and related judgements made by others with regards to their uptake based on the previously acknowledged gender norms that persist. Furthermore, it would be interesting to explore how the daily dynamics of managing work and family responsibilities play out on a daily basis for those with alternative family arrangements, for example LBGT couples where 
gender roles and stereotypes would not be pre-determined, particularly in relation to the occurrence of maternal gatekeeping. Future research should therefore explore the daily impact of flexible working for those with alternative family arrangements.

Participants in the current study were also primarily white, middle class couples with access to full-time employment. Cultural factors can influence the variables involved in workfamily conflict for dual-earner couples in a variety of ways. For example, culture can influence the meaning and relative priority of work and family (Lewis, 1999) and may also have an impact on the willingness to accept support. Furthermore, cultures differ in beliefs about whether balancing work and family is a collective or individual responsibility (Lewis, 1999). Beyond this, individuals from under-represented groups often experience unique career issues, such as stereotyping, restricted opportunities and other stresses that are likely to have an impact on their experiences of work, as well as their experiences of trying to balance this with having a family (Allen et al, 2000; Ozbiligin et al, 2011). Therefore, it is important that future research addresses these issues by including studies using a more diverse range of participants. This diversity has been called for from elsewhere within the work-family conflict literature (e.g. Smith, 1993, Greenhaus, 2008).

In conclusion, a more nuanced account of the everyday experiences of couples seeking to manage the complexity of work and life can highlight important differences in terms of how family-friendly policies are experienced in practice, gender disparity within these daily experiences and related implications for policy and practice. Future research exploring the daily experiences of diverse family types in the use of family-friendly policies, particularly with a focus on gender disparity, gender norms and gatekeeping behaviours, would further enhance our understanding of how such policies work in practice for a variety of individuals 
and families and would subsequently lead to more inclusive and effective policy recommendations.

[Type here] 
References

ACAS (2013) The right to apply for flexible working: a short guide for employers, working parents and carers. http://www.acas.org.uk/media/pdf/m/p/Right-to-apply-forflexible-working-a-short-guide.pdf. [Accessed 22 September 2013]

Allen, T. D. (2001). Family-supportive work environments: The role of organizational perceptions. Journal of Vocational Behavior, 58 (3), 414-435. doi: 10.1006/jvbe.2000.1774

Allen, S. M., \& Hawkins, A. J. (1999). Maternal gatekeeping: Mothers' beliefs and behaviors that inhibit greater father involvement in family work. Journal of Marriage and the Family, 61(1), 199-212. doi: http://dx.doi.org/10.2307/353894

Bakker, A. B., Westman, M., \& van Emmerik, I. J. H. (2009) Advancements in crossover theory, Journal of Managerial Psychology, 24, 206-219. doi: 10.1108/02683940910939304

Beauregard, T. A., \& Henry, L. C. (2009). Making the link between work-life balance practices and organizational performance. Human resource management review, 19(1), 9-22. doi: 10.1016/j.hrmr.2008.09.001

Beitel, A. H., \& Parke, R. D. (1998). Paternal involvement in infancy: The role of maternal and paternal attitudes. Journal of Family Psychology, 12(2), 268-288. doi: $10.1037 / 0893-$ $\underline{3200.12 .2 .268}$

Blustein, D. L. (2001) The interface of work and relationships: Critical knowledge for 21st century psychology. The Counselling Psychologist, 29, 179-192. doi: $10.1177 / 0011000001292001$ 
Brandth, B., \& Kvande, E. (2001). Flexible work and flexible fathers. Work, Employment \& Society, 15(2), 251-267. doi: 10.1177/09500170122118940

Brescoll, V. L., Glass, J., \& Sedlovskaya, A. (2013). Ask and Ye Shall Receive? The Dynamics of Employer-Provided Flexible Work Options and the Need for Public Policy. Journal of Social Issues, 69(2), 367-388. doi: 10.1111/josi.12019

Brough, P., O'Driscoll, M., \& Kalliath, T. (2005). The ability of 'family-friendly' organizational resources to predict work-family conflict and job and family satisfaction. Stress and Health, 21, 223-234. doi: 10.1002/smi.1059

Burnett, S. B., Gatrell, C. J., Cooper, C. L. \& Sparrow, P. (2010). Well-balanced families?: A gendered analysis of work-life balance policies and work family practices. Gender in Management: an International Journal, 25(7), 534-49. doi:

\section{$\underline{10.1108 / 17542411011081356}$}

Butler A, Grzywacz J, Bass B, \& Linney K (2005) Extending the demands -control model: A daily diary study of job characteristics, work-family conflict and work-family facilitation. Journal of Occupational and Organizational Psychology 78: 155-169. doi: $10.1348 / 096317905 \times 40097$

Casper, W. J., Eby, L. T., Bordeaux, C., Lockwood, A. \& Lambert, D. (2007) A review of research methods in IO/OB work-family research, Journal of Applied Psychology 92 (1): 28-43. doi: 10.1037/0021-9010.92.1.28

Coronel, J.M., Moreno, E. \& Carrasco, M.J. (2010) Work-family conflicts and the organizational work culture as barriers women educational managers. Gender, Work \& Organization, 17 (2) 219-39. doi: 10.1111/j.1468-0432.2009.00463.x 
Crompton, R., Brockmann, M. \& Lyonette, C. (2005) 'Attitudes, Women's Employment and the Domestic Division of Labour: A Cross-National Analysis in Two Waves', Work, Employment and Society 19(2): 213-33. doi: 10.1177/0950017005053168

Crouter, A. C., \& Manke, B. (1997). Development of a typology of dual-earner families: A window into differences between and within families in relationships, roles, and activities. Journal of Family Psychology, 11(1), 62-75. doi: 10.1037/08933200.11.1.62

Duxbury, L. E., \& Higgins, C. A. (1991). Gender differences in work-family conflict. Journal of applied psychology, 76(1), 60-74. doi:10.1037/0021-9010.76.1.60

Eby, L .T., Casper, W., Lockwood, A., Bordeaux, C., \& Brinley, A. (2005) Work and family research in IO/OB: Content analysis and review of the literature (1980-2002), Journal of Vocational Behavior 66: 124-197. doi: 10.1016/j.jvb.2003.11.003

Equality and Human Rights Commission (EHRC) Talent not Tokenism: The business benefits of workforce diversity. Report by the Confederation of British Industry (CBI) and the Trades Union Congress (TUC), June 2008. Available from:

http://www.equalityhumanrights.com/uploaded files/Employers/talentnottokenism .. $\mathrm{pdf}$

Fenner, G. H., \& Renn, R. W. (2010). Technology-assisted supplemental work and work-tofamily conflict: The role of instrumentality beliefs, organizational expectations and time management. Human relations, 63(1), 63-82. doi:10.1177/0018726709351064

Gatrell, C. (2005), Hard Labour: the Sociology of Parenthood, Maidenhead: Open University Press. 
Gatrell, C. (2007) A fractional commitment? Part-time employment and the maternal body, International Journal of Human Resource Management, 18(3), 462-474. doi: $10.1080 / 09585190601167813$

Gatrell, C. \& Cooper, C. (2008) Work-life balance: working for whom? European Journal of International Management, 2 (1), 71-86. doi: 10.1504/EJIM.2008.01629

Greenglass, E. R., Pantony, K. L., \& Burke, R. J. (1988). A gender-role perspective on role conflict, work stress and social support. Journal of Social Behavior \& Personality, 3(4), 317-328.

Greenhaus J H (2008) Innovations in the study of the work-family interface: Introduction to the special section, Journal of Occupational and Organizational Psychology 81 (3), 343-348. doi: 10.1348/096317908X332135

Hammer, L.B., Allen, E. \& Grigsby, T.D. (1997) Work-family conflict in dual earner couples: Within individual and crossover effects of work and family. Journal of Vocational Behavior, 50 (2), 185-203. doi: 10.1006/jvbe.1996.1557

Hammer, L. B., Neal, M. B., Newsom, J., Brockwood, K. J., \& Colton, C. (2005). A longitudinal study of the effects of dual-earner couples' utilization of family-friendly workplace supports on work and family outcomes. Journal of Applied Psychology, 90 (4), 799810. doi: $\underline{10.1037 / 0021-9010.90 .4 .799}$

Harkness, S. (2008) The household division of labour: changes in families allocation of paid and unpaid work. In: J. Scott, S. Dex and H. Joshi (Eds.), Women and employment: Changing lives and new challenges, pp. 234-267. Edward Elgar, Cheltenham. ISBN 9781847202499 
Hauser, O. (2012). Pushing Daddy Away? A Qualitative Study of Maternal Gatekeeping. Qualitative Sociology Review, 8(1), 34-59.

Hegewisch, A., \& Gornick, J. C. (2011) The impact of work-family policies on women's employment: a review of research from OECD countries. Community, Work \& Family, 14(2), 119-138. doi: 10.1080/13668803.2011.571395

Hill, J. E., Grzywacz, J. G., Allen, S., Blanchard, V. L., Matz-Costa, C., Shulkin, S., \& PittCatsouphes, M. (2008). Defining and conceptualizing workplace flexibility. Community, Work and Family, 11(2), 149-163. doi: $10.1080 / 13668800802024678$

Holt, H., \& Lewis, S. (2011). 'You Can Stand on Your Head and Still End Up with Lower Pay': Gliding Segregation and Gendered Work Practices in Danish 'Family-friendly' Workplaces. Gender, Work \& Organization, 18(1), 202-221. doi: 10.1111/j.14680432.2009.00501.x

Kan, M. Y., \& Gerhsuny, J. (2010). Gender segregation and bargaining in domestic labour: Evidence from longitudinal time-use data. Gender Inequalities in the 21st Century. New barriers and continuing constraints, 153-173. ISBN 9781848444386 (hbk.)

Kelliher, C., \& Anderson, D. (2010). Doing more with less? Flexible working practices and the intensification of work. Human Relations, 63(1), 83-106. doi:10.1177/0018726709349199

Kersley, B., Alpin, C., Forth, J., Bryson, A., Bewley, H., Dix, G., et al. (2006). Inside the workplace: Findings from the 2004 Workplace Employment Relations Survey. London: Routledge. ISBN 0415378133 
Kilzer, G., \& Pedersen, D. E. (2011). The division of child care among couples with young children: An empowerment model. The Social Science Journal, 48(2), 345-355. doi: 10.1016/j.soscij.2010.11.012

King, N. (2004) Using templates in the thematic analysis of text. In: Cassell, C. and Symon, G. (Eds.) Essential Guide to Qualitative Methods in Organizational Research. London: Sage. ISBN 0761948880

Kossek, E. E., Lewis, S., \& Hammer, L. B. (2010) Work-life initiatives and organizational change: Overcoming mixed messages to move from the margin to the mainstream, Human Relations, 63 (1), 3-19. doi:10.1177/0018726709352385

Kossek, E.E., \& Ozeki, C. (1998) Work-family conflict, policies, and the job-life satisfaction relationship: A review and directions for organizational behavior-human resources research. Journal of applied psychology, 83(2), 139. doi: $\underline{10.1037 / 00219010.83 .2 .139}$

Kulik, L., \& Tsoref, H. (2010). The entrance to the maternal garden: Environmental and personal variables that explain maternal gatekeeping. Journal of Gender Studies, 19(3), 263-277. doi:10.1080/09589236.2010.494342

Lewis, S., Brannen, J., \& Nilsen, A. (2009). Work, family and organisations in transition: setting the context. Work, families and organisations in transition. European Perspectives, 1-16. ISBN 9781847422200

Lewis, S., \& Humbert, L. (2010). Discourse or reality?:“Work-life balance”, flexible working policies and the gendered organization. Equality, Diversity and Inclusion: An International Journal, 29(3), 239-254. doi: 10.1108/02610151011028840 
Massarelli, N., \& Wozowczyk, M. (2009). European Union Labour Force Survey-Annual results 2008. Issue number, 33.

Meyer, C. S., Mukerjee, S., \& Sestero, A. (2001). Work-life benefits: Which ones maximize profits? Journal of Managerial Issues, 13(1), 28-44.

Moen, P., \& Sweet, S. (2002). Two careers, one employer: Couples working for the same corporation. Journal of Vocational Behavior, 61(3), 466-483. doi:10.1006/jvbe.2002.1886

Moen, P., \& Yu, Y. (2000). Effective work/life strategies: Working couples, work conditions, gender, and life quality. Soc. Probs., 47, 291. doi: 10.1525/sp.2000.47.3.03x0294h

Morehead, A. (2005) Beyond Preference and Choice: How Mothers Allocate Time to Work and Family. Paper presented to 'Families Matter' Conference, Australian Institute of Family Studies, 9-11th February

Perälä-Littunen, S. (2007). Gender equality or primacy of the mother? Ambivalent descriptions of good parents. Journal of Marriage and Family, 69(2), 341-351. doi: 10.1111/j.1741-3737.2007.00369

Poppleton, S., Briner, R. B., \& Kiefer, T. (2008) The roles of context and everyday experience in understanding work-non-work relationships: A qualitative diary study of whiteand blue-collar workers, Journal of Occupational and Organizational Psychology 81 (3), 481-502. doi: 10.1348/096317908X295182

Posig, M., \& Kickul, J. (2004). Work-role expectations and work family conflict: gender differences in emotional exhaustion. Women in Management Review, 19(7), 373386. doi: $\underline{10.1108 / 09649420410563430}$ 
Pruett, M. K., Arthur, L. A., \& Ebling, R. (2006). Hand That Rocks the Cradle: Maternal Gatekeeping after Divorce, The. Pace L. Rev., 27, 709-739.

Puhlman, D. J., \& Pasley, K. (2013). Rethinking maternal gatekeeping. Journal of family theory \& review, 5(3), 176-193. doi: 10.1111/jftr.12016

Radcliffe, L. S. (2013). Qualitative diaries: uncovering the complexities of work-life decisionmaking. Qualitative Research in Organizations and Management: An International Journal, 8(2), 163-180. doi: 10.1108/QROM-04-2012-1058

Radcliffe, L. S., \& Cassell, C. (2014). Resolving couples' work-family conflicts: The complexity of decision making and the introduction of a new framework. Human Relations, 67(7), 793-819. doi:10.1177/0018726713506022

Rapoport, R., Bailyn, L., Fletcher, J. \& Pruitt, B. (2002) Beyond Work-Family Balance: Advancing Gender Equity and Work Performance. Chichester: Wiley.

Rochlen, A. B., McKelley, R. A., \& Whittaker, T. A. (2010). Stay-at-home fathers' reasons for entering the role and stigma experiences: A preliminary report. Psychology of Men \& Masculinity, 11(4), 279-285. doi: $10.1037 / a 0017774$

Rosenbaum, M., \& Cohen, E. (1999). Equalitarian marriages, spousal support, resourcefulness, and psychological distress among Israeli working women. Journal of vocational behavior, 54(1), 102-113. doi: 10.1006/jvbe.1998.1644

Russell, H., O'Connell, P. J., \& McGinnity, F. (2009). The impact of flexible working arrangements on work-life conflict and work pressure in Ireland. Gender, Work \& Organization, 16(1), 73-97. doi: 10.1111/j.1468-0432.2008.00431.x 
Sanz-Vergel, A. I., Rodríguez-Muñoz, A., \& Nielsen, K. (2014). The thin line between work and home: the spillover and crossover of daily conflicts. Journal of Occupational and Organizational Psychology. doi: 10.1111/joop.12075

Shepard, E., Clifton, T. \& Kruse, D. (1996). Flexible work hours and productivity: Some evidence from the pharmaceutical industry, Industrial Relations, 35(1), January, 12339.

Trinder, L. (2008). Maternal gate closing and gate opening in postdivorce families. Journal of Family Issues, 29(10), 1298-1324. doi:10.1177/0192513X08315362

van Daalen, G., Sanders, K., \& Willemsen, T. M. (2005). Sources of social support as predictors of health, psychological well-being and life satisfaction among Dutch male and female dual-earners. Women \& health, 41(2), 43-62. doi:10.1300/J013v41n02_04

Wanrooy, B. V., Bewley, H., Bryson, A., Forth, J., Freeth, S., Stokes, L., \& Wood, S. (2013). The 2011 workplace employment relations study: First findings.

Wise, S. \& Bond, S. (2003). Work-life policy: does it do exactly what it says on the tin? Women in Management Review, 18(1/2), 20-31. doi: 10.1108/09649420310462307

Yavas, U., Babakus, E., \& Karatepe, O. M. (2008). Attitudinal and behavioral consequences of work-family conflict and family-work conflict: does gender matter? International Journal of Service Industry Management, 19(1), 7-31. doi:

$\underline{10.1108 / 09564230810855699}$

[Type here] 
Table 1: Overview of participants

\begin{tabular}{lllll}
\hline & Names & Children & Occupations & Work Flexibility \\
\hline Couple 1 & Lucy \& Paul & Rachel - 8 & Paul - civil engineer & Paul - Flexi-time \& works from home 2 days/wk \\
& & Kieran - 5 & Lucy - Social worker & Lucy - Part-time but with little flexibility \\
& & James - 2 & & \\
\hline Couple 2 & Sylvia \& Ben & Fiona - 11 & Ben - machine operator & Ben - works nights \\
& & & Sylvia - personal assistant in healthcare & Sylvia - part-time and flexi-time \\
\hline Couple 3 & Hannah \& Nigel & June - 17 & Nigel - engineer & Hannah - limited flexibility but working hours \\
& & Sam - 14 & Hannah - payroll manager & arranged around school times \\
\hline
\end{tabular}


Liam - 8

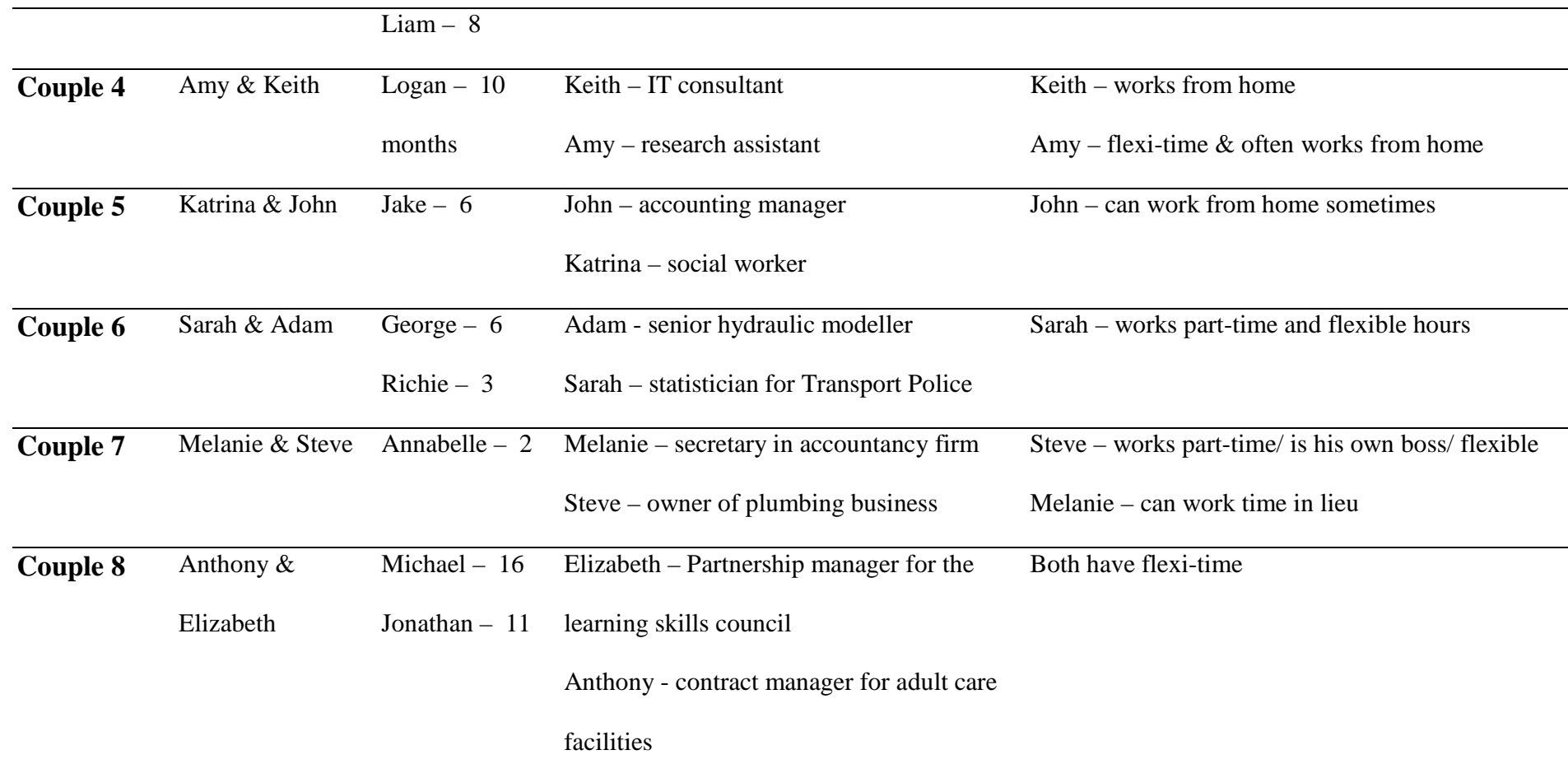

\begin{tabular}{|c|c|c|c|c|}
\hline Couple 9 & Julia \& Tom & $\begin{array}{l}\text { Lewis }-8 \\
\text { Nina }-4\end{array}$ & $\begin{array}{l}\text { Julia - personal assistant } \\
\text { Tom - graphic designer }\end{array}$ & Julia - works part-time \\
\hline Couple 10 & Emma \& Richard & $\begin{array}{l}\text { Andrew - } 11 \\
\text { Melissa - } 10 \\
\text { Joanna - } 10\end{array}$ & $\begin{array}{l}\text { Emma - secretary } \\
\text { Richard - engineer }\end{array}$ & $\begin{array}{l}\text { Richard - works flexi-time } \\
\text { Emma - works part-time }\end{array}$ \\
\hline Couple 13 & Marissa \& Nick & $\begin{array}{l}\text { Beth }-12 \\
\text { Tobey }-8\end{array}$ & $\begin{array}{l}\text { Marissa - development manager for the } \\
\text { voluntary service charity } \\
\text { Nick - production worker }\end{array}$ & Marissa - works flexi-time \\
\hline Couple 14 & Dave \& Emily & $\begin{array}{l}\text { Kyle }-5 \\
\text { Suzanne - } 2\end{array}$ & $\begin{array}{l}\text { Emily - healthcare assistant at pharmacy } \\
\text { Dave - head chef }\end{array}$ & Emily - works part-time \\
\hline
\end{tabular}




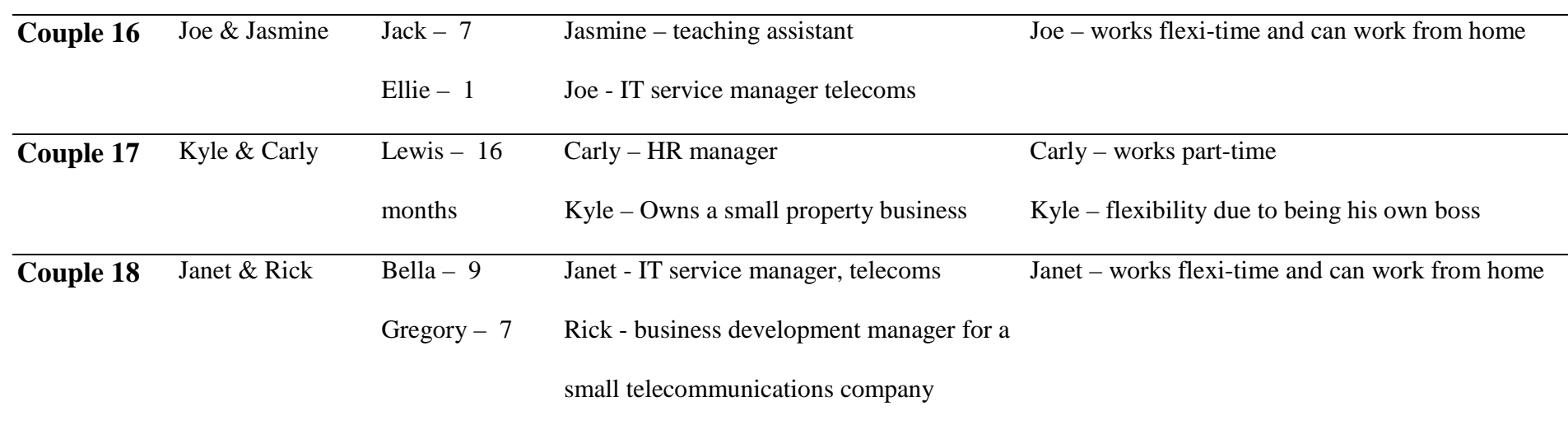

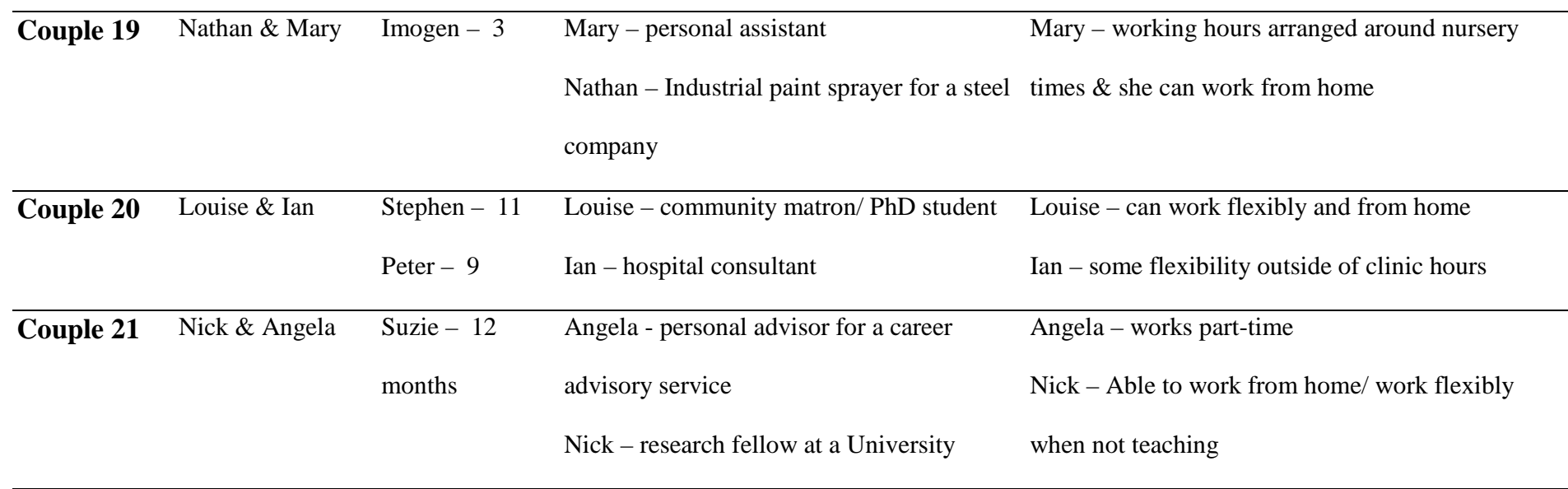

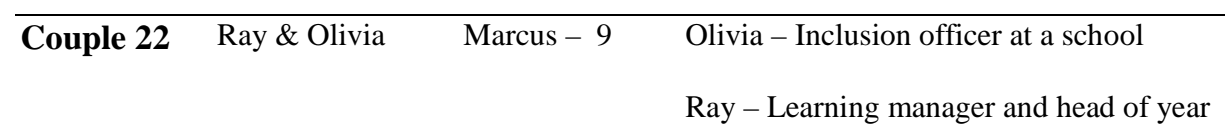

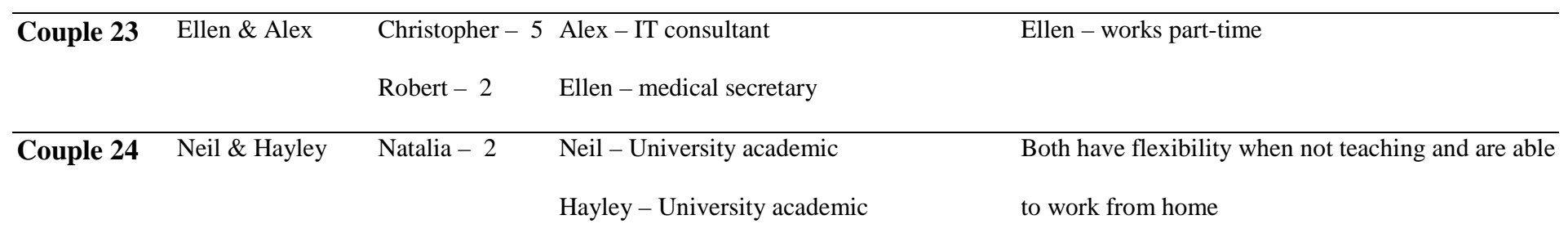

